\title{
On Chinese Cultural Subjectivity Regarding Exemplary and Narrative Language: Based on Ricoeur's Research of Narrative
}

\author{
Wang Wen-Sheng \\ National Chengchi University, Taipei City, Taiwan
}

\begin{abstract}
Exemplary language can, on the one hand, assist a listener to understand what a speaker intends to express, and, on the other hand, provoke a kind of practical force to the listener. Exemplary language is everywhere in our daily life, such as the bedtime stories told by a mother to her child, literary works, and judicial precedents. Many Western philosophers have expounded on this type of language. Exemplary language has become a topic for philosophical discussions. In Chinese classics, there are many expressions using exemplary language, but in different forms. Was there any philosophical reflection on these exemplary languages? The differences between the Chinese and the Western exemplary language initiate our discussion about the different subjectivity of exemplary language, or narrative subjectivity, for narrative will be discussed in this article as an extraordinary exemplary language. As a kind of exemplary language, narrative is analyzed by Ricoeur into two elements: time and meaning. Is his analysis also valid for Chinese narrative language? Can we discuss the difference of narrative subjectivity according to these two elements? The author is going to trace the origins of different subjectivity by analyzing distinct ways of creating characters/words which determinate different language forms in Chinese and the Western culture. The author finds that "linear time" (or objective time) still plays a significant role in the Western culture; by contrast, subjective time seems more dominant in Chinese culture. This also determines the narrative time for Chinese. As for the meaning, there are different purposes and ways of using narrative in Chinese culture and the Western culture, which are reflected, for example, in the different purposes of the Chinese and Western drama. This article aims to explore Chinese narrative subjectivity based on Ricoeur's research of narrative.
\end{abstract}

Keywords: exemplary language, narrative, Confucianism, Zhuangzi, narrative time, narrative meaning

\section{Introduction}

Exemplary language can, on the one hand, assist a listener to understand what a speaker intends to express, and, on the other hand, provoke a kind of practical force to the listener. Exemplary language is everywhere in our daily life, such as the bedtime stories told by a mother to her child, literary works, and judicial precedents. Many Western philosophers have expounded on this type of language. In other words, exemplary language has become a topic for philosophical discussions. Narrative is a kind of exemplary language. The constituents of narrative: time and meaning, can be those according to which we discuss the subjectivity of the exemplary language.

In Chinese classics, there are many expressions using exemplary language. Do they also have the aforementioned effects? Has there been any philosophical reflection on these exemplary languages? When

Wang Wen-Sheng, Prof. Dr. of Philosophy, Department of Philosophy, National Chengchi University, Taipei City, Taiwan. 
Zhuangzi pointed out "words that are metaphorical (Yu yan, 寓言)", “words from valued writers/figures (Chong yan, 重言)", and “words like the water that daily issues from the cup (Zhi yan, 厄言)", has he made a philosophical reflection on these exemplary languages? Besides, in the Analects and the Mencius, there is no lack of exemplary language. Do they have any philosophical discourse on it? How about other Chinese classics?

The differences between the Chinese and the Western exemplary language initiate our discussion about the relation between language and culture. Is language a crucial element that constitutes a culture? Or vice versa? Language itself consists of pre-linguistic elements, such as the level of human existence (Dasein) or that of Being, which is embodied in language. In this regard, Heidegger's critique of Cassirer could be true: In relation to Being, language is not terminus ad quem, but terminus a quo. Thus, we must investigate the pre-linguistic level, so that we can discuss the subjectivity of the exemplary languages in different cultures.

This article is going to trace the origins of different subjectivity by analyzing distinct ways of creating characters/words in Chinese and the Western culture. A Chinese character is with one syllable and one meaning, and normally every word in a Western language is with multiple syllables and one meaning. There have been many discussions about this difference. The Western words with multiple syllables are composed in accordance with linear time, which determine the logic structure. Language has long served as a tool for the Western people to justify a claim or sentence (logon didonai) since the Ancient Greek. The logic structure needed when doing so may have something to do with the multi-syllable words used in Western languages. However, in the Western culture, there are exemplary language and poetic language as well, which can also express a reasonable meaning just as what logon didonai does. This type of language is not a mainstream way of expression in the West, but is very common in Chinese classics. This phenomenon is probably due to the type of Chinese characters, which have been created without the concept of linear time and logic structure. Nevertheless, is exemplary language carried by another form of time? Ricoeur intends to analyze the time in a narrative, which is a type of exemplary language. But it is to be noticed that the time in a narrative might differ because of varied types of characters/words and subjectivity. As for the other element constituting a narrative, "meaning", it can also be discussed based on the purposes of using narrative and the theoretical backgrounds in different cultures.

This article aims to explore Chinese narrative subjectivity based on Ricoeur's research of narrative.

\section{Western Exemplary Language}

It is called doxa (opinion) in Ancient Greek philosophy whether one uses examples to strengthen the expression of an idea or relies completely on pure examples to communicate. Doxa was considered to be an opinion that could not become real knowledge. Such a criticism was made by Socrates when he pointed out that the Sophists only gave some examples instead of providing definitions when describing things. The doxa that is not qualified to be knowledge reveals the deficiency of exemplary language. However, if one offers some examples based on the knowledge that has been constructed, it can be helpful for the communication and practical usage of the knowledge.

Rhetoric by Aristotle raised the concepts of paradéigma (a pattern, example, or sample) and enthúmema (rhetorical syllogism), which are different from the induction and syllogism based on logic. Rhetoric starts from a doxa, with no need to put forward the premise first. As a result, paradéigma takes advantage of a real case to propose an idea, which will always be demonstrated by the real case or doxa. However, this does not mean that 
Rhetoric only provides opinions, or doxa. In fact, the theoretical discourse has been intuitively accepted through the words being said. The persuasiveness of Rhetoric is the perfect example proving that the exemplary language can help with communication and is definitely effective.

Later, in Kritik der reinen Vernunf, Kant (1976) stated that the ability of judging is crucial for applying traditional logic to the object of experience. In this case, an example is needed as a practice to develop this ability. That is why Kant has said "examples are thus the go-cart of the judgment" (Kant, 1976, pp. 134-136). He also stated in Kritik der Urteilskraft that an empirical concept that is supposed to be real is based on intuition towards an example (Kant, 1974). A rational concept, which can be thought but not aesthetically intuited, can be real only with an allegorical symbol. The example provided by Kant is that when a monarchy is governed according to the laws established by its people; it resembles a mentalized body. By contrast, when a monarchy is governed by the absolute will of an individual, it resembles a mill. The symbols used by Kant (body and mill) serve as allegories of the "rule of law" and "autocracy" (Kant, 1974, pp. 255-257).

Later, Arendt also cited Kant's words: "examples are thus the go-cart of judgment". Though the words Arendt used was not focusing on applying traditional logic to objects of experience. Instead, she intended to emphasize that aesthetic judgment as well as the moral and political judgments derived from it should be based on personal experiences and examples (Arendt, 2003). Such examples should be the people or things that are widely recognized and valued in the history to have qualities, such as beauty, goodness, and justice. To illustrate the concept, Arendt has said that an exemplary grand bridge enabled herself to recognize and appreciate a grand bridge in front of her. Other examples included Achilles as the example of brevity, Jesus as the example of goodness, and King Solomon as the example of a wise man (Arendt, 2003; Arendt, 2012).

Arendt took the concept of allegory proposed by Kant as a kind of "metaphor", which is different from an example. When we try to understand a phenomenal world, what we need is to just think based on common sense and use examples to demonstrate the concept. When an abstract concept is elaborated on with a specific example, it becomes easier to understand. However, in another situation when reason should go beyond the phenomenal world to lead us to the realm of speculation, metaphor can help us understand rational ideas, which do not correspond with intuition. The allegory of a machine used by Kant to symbolize and illustrate the absolute monarchy was categorized by Arendt as a metaphor (Arendt, 1976).

The author has elaborated on how examples assist us in recognizing and understanding empirical concepts with the cases of Kant and Arendt. What should be noticed is that the concepts of "grandness", "beauty", and "goodness", according to Arendt, are "examples" representing certain ideas. Therefore, we would like to ask: Do they only play an assisting role in understanding empirical concepts? Do they actually represent a priori or reason? Is it appropriate to regard an example as a symbol and an analogy of reason? To be more specific, is it possible for an example to mean much more and be considered the kind of "metaphor" stated by Arendt?

In fact, Kant's discourse about examples used in the aesthetic judgment along with the studies done by Gadamer indicates that an example is what forms a universal taste while leaving rooms for personal touches. For instance, a tasteful work may be widely recognized as an aesthetic standard. Nevertheless, it is not just a "model" (Muster) to "imitate" (nachahmen) but a principle to be followed by others. This is because an example provides the successors with an idea, or a map, enabling them to find the principle within themselves. Thus, taste is a matter of individual talent (Kant, 1974; Gadamer, 1990). The function of an example is helping us explore and construct our innate taste. An example can represent an a priori concept, whose a priori is 
formed by common sense or sensus communis. The forming process happens incessantly between the subjective and private experience and the objective and universal concept.

According to the discussion above, we can make sense of Arendt's emphasis on narrative. She maintains that "who I am" should be a story told by others based on the "actions" and "speech" of me. When one tells a story, the roles and plots are all examples. As a result, a narrative emphasizing the use of examples is using narrative language to enhance the communication of knowledge and its effects.

Julia Kristeva has elaborated on the "example", on which Arendt puts much attention, using the concept of "narrative". Kristeva maintains that the answer of "who are you", the question asked by Arendt in her The Human Condition, has something to do with one's actions and speech. As for narrative, it serves as the lexis to answer the question and is the history where the actions and speech have taken place (Kristeva, 2001; Arendt, 1958) ${ }^{1}$. For Kristeva, the actions and speech that have happened are turned into a narrative by recalling, that it, "verbalizing" the "plot" to transform facts into "shareable thoughts". However, to form a narrative, the historical fact should be ended and can be identified or recognized as the story of a single protagonist, so that it can be recalled and turned into a meaningful story. Kristeva (2001) pointed out that "the art of narrative, then, resides in the ability to condense the action into an exemplary moment, to extract it from the continuous flow of time, and reveal a who" (p. 17). She elaborates on this statement that the demonstration of the "who" is like an oracular, not speaking nor hiding anything. It just "makes a sign", though "incomplete" and "fragmentary", that "launches an infinite action of interpretation" (Kristeva, 2001, p. 18).

The actions and speech of a person in history are told as a meaningful story. Once it is performed, the story becomes a drama, but a drama may also be based on a fictional story. There is no wonder that Poetics by Aristotle serves as the theoretical foundation for Arendt and Kristeva's discourses that exemplary story plots can be inspiring for the audience and the later generations. The various drama types discussed in Poetics are also categorized by Paul Ricoeur into the big category of narrative.

In addition to adding the narrative of fictional novel to Arendt's historical narrative, Ricoeur also explores the two core elements of narrative: time and the construction of meaning. The time in a narrative is the medium of objective time (as assumed by Aristotle and Kant) and subjective time (as analyzed by Augustine and Husserl's phenomenology). Ricoeur just finds the time of narrative from the within-time-ness (Innerzeitigkeit) of Heidegger, which is also in-between the objective or vulgar time, and the subjective or authentic (eigentlich) time of Dasein (being-there) (Ricoeur, 1988). The construction of meaning is based on the concept of "catharsis" proposed by Aristotle. "Catharsis" is an ethical state achieved by transcending the grief after being challenged by fate. Ricoeur also uses some concepts proposed by Freud, such as "mourning" and "accusation" (Anklagen), to support his argument that narrative follows a "discordant concordance" to construct meaning (Ricoeur, 1984; Kearney, 2004).

Ricoeur has emphasized the importance of Arendt's quotation of Isak Dinesen (in "Action," Chapter 5 of The Human Condition) that "[a]ll sorrows can be borne if you put them into a story or tell a story about them". His interpretation of the quotation is that life is looking for narrative, "because it strives to discover a pattern to

\footnotetext{
${ }^{1}$ According to Arendt, narrative is to turn the intangible public space in action and speech into the tangible public space, because narrative is the traces of action through work (Arendt, 1958, pp. 194, 198-199). Thus, the lexis mentioned by Kristeva here is more like a trace. Since she also pointed out that Arendt and Ricoeur differ in some ways in their narrative discourses, this statement may refer to the fact that Arendt's narrative does not distinguish fictional stories from real history. The stories she tells are parts of the history, because she approaches the issue of narrative focusing on humans' survival in the world (Kristeva, 2001, p. $15)$.
} 
cope with the experience of chaos and confusion" (Arendt, 1958, p. 175; Kearney, 2004. pp. 361-362). The abovementioned cases of Aristotle and Freud are provided with a theoretical foundation for such discovery.

Exemplary language is not a mainstream way of philosophical discourse in the West and this kind of expression is called "indirect communication". In addition to the philosophers mentioned above, there are still many representative ones, including Augustine, Kierkegaard, and Nietzsche. They often demonstrate their philosophical thoughts indirectly by means of allegory, metaphor, and irony. It should be noticed that the word "demonstration" and "proof" are not exactly the same. We regard the metaphorical language discussed above as an exemplary language in a broad sense. This kind of language, which is a mainstream in Chinese language and culture, will be our main focus in the next section.

\section{Eastern Exemplary Language}

\section{The Exemplary Language and "Mirror-Reflection” Subjectivity of Zhuangzi}

The "Yu yan" (寓言) along with “Tian xia” (天下) in the miscellaneous chapters of the Zhuangzi (Huang, 1974/2011; C. Tzu \& L. Tzu, 1962) ${ }^{2}$ are regarded by Wan Fu zhi (王夫之) as the preface of the book, which means the articles both demonstrate a certain common feature in the Zhuangzi. In the beginning of "Yu yan", the author says

[o]f my sentences nine in ten are metaphorical; of my illustrations seven in ten are from valued writers. The rest of my words are like the water that daily fills the cup, tempered and harmonised by the Heavenly element in our nature. (C. Tzu \& L. Tzu, 1962, p. 142)

These words above mean that the "metaphorical language" (that is, Yu yan) accounts for 90 percent of the language types used in the Zhuangzi. Besides, 70 percent of these metaphorical stories consist of words valued by most people to indirectly state the author's opinions. These words are usually attributed to some great figures, such as Huang di (Yellow Emperor), Yao, Shun, Confucius, and Yan Hui. Moreover, just like the water in a cup, "talking" can change its form according to different situations. As a result, the "talk" is generated every day and the argument made by it is never fixed, while it always reflects the principles of nature. Based on the earlier demonstration of exemplary language, we know that ninety percent of the Zhuangzi is composed of such language. Compared with "Tian xia", "Yu yan" is even more noteworthy because in this article, Zhuangzi explains the reason for using exemplary language.

Zhuangzi explains the reason for using metaphorical language by saying

[t] he nine sentences in ten which are metaphorical are borrowed from extraneous things to assist the comprehension of my argument. There is an example. A father is not an ideal matchmaker for his own son. It is better for another man to praise the son than for his father to do so. Therefore, it is better to blame somebody through others words rather than my own words. (C. Tzu \& L. Tzu, 1962, p. 142)

Metaphorical language is used to talk one thing through another thing. The types of metaphorical language Zhuangzi used include similes and metaphors. The words above only state a partial purpose of using metaphorical language. Zhuangzi should have noticed the other effects and meanings of using exemplary language as we have discussed in the former section. We have emphasized that an "example" can be followed by successors, which is what "words of valued writers" can do. For Zhuagnzi, "[t]he seven out of ten

\footnotetext{
${ }^{2}$ The Chinese text is from Huang, 1974/2011. The English versions of the Chinese texts cited in this article are translated by James Legge (C. Tzu \& L. Tzu, 1962).
} 
illustrations taken from valued writers are designed to put an end to disputations. Those writers are the men of hoary eld" (C. Tzu \& L. Tzu, 1962, p. 142). The words said by the elder and knowledgeable, people can stop disputations, but can such words provide "signs" to inspire the listeners or let them develop their own talents?

As pointed out by $\mathrm{Hu}$ Yuan-jun, "metaphorical language and words from valued writers are all words like the water that daily fills the cup". This means with these two kinds of language, Zhuangzi avoids giving his own opinions directly. Not giving one's own opinions seems "without words". That is why Zhuangzi says "[b]ut without words there is an agreement (in principle). That agreement is not effected by words, and an agreement in words is not effected by it. Hence it is said, 'Let there be no words"' (C. Tzu \& L. Tzu, 1962, p. 143). "Agreement" is to reflect the principle of nature. If one can master the art of "no words" or "not talking", then "[w]ords like the water that daily issues from the cup, and are harmonised by the Heavenly Element (of our nature), may be carried on into the region of the unlimited, and employed to the end of our years" (C. Tzu \& L. Tzu, 1962, p. 143). Nonetheless, borrowing others words and changing the form of language depending on different situations are still a kind of "talking". Therefore, Zhuangzi continues to say "[s]peech does not need words. One may speak all his life, and not have spoken a (right) word; and one may not have spoken all his life, and yet all his life been giving utterance to the (right) words" (C. Tzu \& L. Tzu, 1962, p. 143). What should be asked here is that why changing the form of language can reflect the principle of nature? The answer will be:

[a]ll things are divided into their several classes, and succeed to one another in the same way, though of different bodily forms. They begin and end as in an unbroken ring, though how it is they do so be not apprehended. This is what is called the Lathe of Heaven; and the Lathe of Heaven is the Heavenly Element in our nature. (C. Tzu \& L. Tzu, 1962, p. 144)

This is the principle of nature and also the wonder of nature.

Here Zhuangzi also states through Confucius' words that

[m]an receives his powers from the Great Source (of his being), and he should restore them to their (original) intelligence in his life. His singing should be in accordance with the musical tubes, and his speech a model for imitation. When profit and righteousness are set before him, and his liking (for the latter) and dislike (of the former), his approval and disapproval, are manifested, that only serves to direct the speech of men (about him). To make men in heart submit, and not dare to stand up in opposition to him; to establish the fixed law for all under heaven. (C. Tzu \& L. Tzu, 1962, pp. 144-145)

Such words indicate that if one's behavior and speech can follow and reflect the principle of nature, then the power of the "Great Source" will come to him. When the sounds of nature are transformed into human words, which are used to establish laws and regulations, it should be noticed that "language" usually can only force others to obey. To convince others completely, one should talk with more "words like the water in a cup", which follow and reflect the principle of nature. Therefore, words like the water in a cup are the real "signs" provided by exemplary languages like metaphorical language and words from valued writers (or figures). The signs bring an inspiration that when transforming sounds of nature into human words, one should change the form of speech based on different situations. By doing so, one can avoid expressing his or her own opinions and thus reflect the principle of nature (Heidegger, 1982).

\footnotetext{
${ }^{3}$ This is close to what Heidegger has stated later in Identität und Differenz that language is the Sage (saying) of Being. Since the saying of Being is a kind of "vibration", language should itself vibrate instead of being limited (Heidegger, 1982, p. 49).
} 
A specific "subjectivity" is the prerequisite for expressing one's opinions in this way, that is, quoting others' words, giving up prejudices, and thus changing the form of one's speech according to varied situations. A more famous metaphor used for such subjectivity is a "mirror", which truthfully reflects the nature and behavior of all things (Zhan, 2014). Such subjectivity is fairly similar to that after phenomenological reduction. Based on Husserl's theory, Zahavi (2016), a contemporary phenomenologist, considered this ultimate subjectivity to be a "minimalist" self. This subjectivity passively receives messages from others while preserving its own nature, just like a mirror reflecting things. A mirror just passively reflects the things in front of it. This also has a teleological implication, which is often conveyed by phenomenology. For example, several concepts emphasized by Husserl, such as "passive intentionality" and "instinct", focus on the purpose of one's existence in nature. Heidegger's inclination to this view is more evident. His attitude toward technology is that we should go into the history or fate of Being and let nature reveal itself after all the problems caused by humans' over-revealing actions to nature. By doing so, Heidegger believes that the negative effects brought by technology can be gradually mitigated. Heidegger's theory put emphasis on a kind of primordial ethic, which can also be sensed in Zhuangzi's words. Zhuangzi is often criticized for failing to form normative ethics that can be followed, but in fact, Zhuangzi's philosophical idea does show a teleological principle which put attention to the nature or the fate of beings.

This article intends to explore the Eastern and Western subjectivity focusing on exemplary language, but it is crucial to clarify the nature of such subjectivity before discussing exemplary language. Moreover, since the "words like the water in a cup" represent the kind of speech which will change its form according to different conditions around, metaphorical language and the words from valued figures can also be regarded as this kind of language. After all, Zhuangzi also explains the meaning of the "words like the water in a cup" through Confucius' words. But which kind of exemplary language is used by the Confucians? What is the subjectivity behind it?

\section{Confucian Exemplary Language and Its Subjectivity: Ren (仁)}

We can find amount of metaphorical language and words from valued figures in Confucian classics, but the metaphorical stories in the Zhuangzi seem more fictional than the Confucian ones. For instance, in "Xiao yao you" (逍遥遊), the first one of the seven inner chapters, Zhuangzi tells a story that "[i]n the Northern Ocean there is a fish, the name of which is Kun-I do not know how many $l i$ in size (miles) [...]" (C. Tzu \& L. Tzu, 1962, p. 164). Even "Ying di wang” (應帝王), the last one of the seven inner chapters, also ends with an allegory that "[t]he Ruler of the Southern Ocean was Shu, the Ruler of the Northern Ocean was Hu, and the Ruler of the Centre was Chaos [...]". They are just two of the most representative imaginary stories fabricated by Zhuangzi. Other well-known stories include "Zhuang Zhou Dreaming of a Butterfly", "The Cook Ding Dismembering Cattle", and the "Happy Fish Debate" between Zhuangzi and Hui Shi. All of these stories lead the readers to think outside the box. Unlike the Zhuangzi, most of the metaphors used in Confucian classics are real events. For example, in the Analects (Xie, 1987/2006) ${ }^{4}$, there are metaphorical expressions as follows:

He who exercises government by means of his virtue may be compared to the north polar star, which keeps its place and all the stars turn towards it. (Wei Zheng, p. 1)

\footnotetext{
${ }^{4}$ The Chinese text is from Xie 1987/2006. The Mencius, Da Xue, and Zhong Yong below are from the same source. English versions are translated by James Legge and cited from Chinese Text Project online (Sturgeon, 2011).
} 
I do not know how a man without truthfulness is to get on. How can a large carriage be made to go without the crossbar for yoking the oxen to, or a small carriage without the arrangement for yoking the horses? (Wei Zheng, p. 22)

In the Mencius, there are also examples like:

All the people of the nation will unanimously give it to him. Does your Majesty understand the way of the growing grain? During the seventh and eighth months, when drought prevails, the plants become dry. Then the clouds collect densely in the heavens, they send down torrents of rain, and the grain erects itself, as if by a shoot. When it does so, who can keep it back? Now among the shepherds of men throughout the nation, there is not one who does not find pleasure in killing men. If there were one who did not find pleasure in killing men, all the people in the nation would look towards him with outstretched necks. (Liang Hui Wang I, p. 6)

Therefore the principles of our nature and the determinations of righteousness are agreeable to my mind, just as the flesh of grass and grain-fed animals is agreeable to my mouth. (Gaozi I, p. 7)

Examples can also be found in "Da Xue (The Great Learning)":

In the Book of Poetry, it is said, "The royal domain of a thousand li is where the people rest." In the Book of Poetry, it is said, "The twittering yellow bird rests on a corner of the mound." The Master said, "When it rests, it knows where to rest. Is it possible that a man should not be equal to this bird?" (Da Xue, p. 3) ${ }^{8}$

In "Zhong Yong (The state of equilibrium and harmony)", one can also see metaphorical expressions like:

It is said in the Book of Poetry, "Over her embroidered robe she puts a plain single garment", intimating a dislike to the display of the elegance of the former [...] It is said in the Book of Poetry, "Looked at in your apartment, be there free from shame as being exposed to the light of Heaven”. Therefore, the superior man, even when he is not moving, has a feeling of reverence, and while he speaks not, he has the feeling of truthfulness. (Zhong Yong, p. 33) ${ }^{9}$

The examples in "Da Xue" and "Zhong Yong" can also be regarded as words from valued figures, because they all quote from the Book of Poetry. This writing strategy is commonly used in the Analects and the Mencius. Representative examples include:

It is said in the Book of Poetry, "We should be apprehensive and cautious, as if on the brink of a deep gulf, as if treading on thin ice [...]". (Tai Bo, p. 3, from the Analects) ${ }^{10}$

It is said in the Book of Poetry, "Before the heavens were dark with rain, I gathered the bark from the roots of the mulberry trees, And wove it closely to form the window and door of my nest; Now, I thought, ye people below, Perhaps ye will not dare to insult me." Confucius said, "Did not he who made this ode understand the way of governing?" If a prince is able rightly to govern his kingdom, who will dare to insult him? (Gong Sun Chou I, p. 4, from the Mencius) ${ }^{11}$

The latter one is a quotation from Confucius by Mencius, and there is yet another example: "The relation between superiors and inferiors is like that between the wind and grass. The grass must bend when the wind blows upon it [...]" (Teng Wen Gong I, p. 2). ${ }^{12}$

\footnotetext{
${ }^{5}$ Sturgeon (2011), https://ctext.org/analects/wei-zheng/zh?en=on.

${ }_{7}^{6}$ Sturgeon (2011), https://ctext.org/mengzi/liang-hui-wang-i/zh?en=on.

7 Ibid., https://ctext.org/mengzi/gaozi-i/zh?en=on.

8 Ibid., https://ctext.org/liji/zhong-yong/zh?en=on.

${ }^{9}$ Ibid., https://ctext.org/liji/zhong-yong/zh?en=on.

${ }^{10}$ Sturgeon (2011), https://ctext.org/analects/tai-bo/zh?en=on.

11 Ibid., https://ctext.org/mengzi/gong-sun-chou-i/zh?en=on.

12 Ibid., https://ctext.org/mengzi/teng-wen-gong-i/zh?en=on.
} 
What should also be noticed is that Confucianism lacks "words like the water in the cup", which suggests that the subjectivity of Confucianism is not a "mirror-reflection" one. Though Zhuangzi has emphasized his own thoughts through conversations between Confucius and his disciple, Yan Hui, the Confucian subjectivity, unlike that of Zhuangzi, does not transform to the ever-changing nature.

However, such difference is not surprising since Zhuangzi and Confucius have distinct approaches to the secular world. For instance, similar comments appear in “Ren jian shi” (人間世) of the Zhuangzi as well as the Analects:

O Feng! O Feng! How is your virtue degenerated! As to the past, reproof is useless; but the future may still be provided against. Give up your vain pursuit. Give up your vain pursuit. Peril awaits those who now engage in affairs of government. (Wei Zi, p. 5, from the Analects) ${ }^{13}$

These words suggest that Confucius still embraces the ideal that he can have others follow in his footsteps by behaving morally and nobly himself. This is the Confucius deemed to be one "who knows the impracticable nature of the times and yet will be doing in them" (Xian Wen, p. 41) ${ }^{14}$. Perhaps Confucius does know that a person can actually do nothing as he has asked, "[d]oes Heaven speak? The four seasons pursue their courses, and all things are continually being produced, but does Heaven say anything?" This is why he has said "I would prefer not speaking". Nevertheless, it concerns Zi Gong that "[i]f you, Master, do not speak, what shall we, your disciples, have to record?" (Yang Huo, p. 17) ${ }^{15}$ Zi Gong's question may also be Confucius' concern. Especially when the world is in a chaos and a reform is needed, Confucius feels that "[i]t is impossible to associate with birds and beasts, as if they were the same with us. If I associate not with these people - with mankind - with whom shall I associate?" (Wei Zi, p. 10) ${ }^{16}$ This can be attributed to "a mind which cannot bear to see the sufferings of others", which is elaborated later by Mencius. From this we know that the subjectivity of Confucianism is no longer "mirror-reflection". Instead, Confucian teachings are based on Ren (仁), which may explain why the "words like the water in a cup" are barely used in Confucianism.

\section{Poetry as History}

In these Confucian classics, there is no explanation for the use of different kinds of languages (like what Zhuangzi has done in "Yu yan"). However, when regarding such metaphorical expressions as a kind of poetic language, we can find direct praise of poetry in the Analects. Here are two of the examples:

With one like Ci, I can begin to talk about the odes [that is, poetry]. I told him something in the past, and he knew what will possibly be in the future. (Xue Er, p. 15) ${ }^{17}$

The Master said, "My children, why do you not study the Book of Poetry? The Odes serve to stimulate the mind. They may be used for purposes of self-contemplation. They teach the art of sociability. They show how to regulate feelings of resentment. From them you learn the more immediate duty of serving one's father, and the remoter one of serving one's prince. From them we become largely acquainted with the names of birds, beasts, and plants." (Yang Huo, p. 9) ${ }^{18}$

The second paragraph shows several functions of poetic language, but the most essential one is "Xin" (興), "to stimulate the mind". With the function of "Xin", poetic language can make readers or listeners feel, inspire

13 Ibid., https://ctext.org/analects/wei-zi/zh?en=on.

${ }_{15}$ Sturgeon (2011), https://ctext.org/analects/xian-wen/zh?en=on.

15 Ibid., https://ctext.org/analects/yang-huo/zh?en=on.

${ }_{17}^{16}$ Ibid., https://ctext.org/analects/wei-zi/zh?en=on.

${ }_{17}$ Modified based on James Legge's translation. Ibid., https://ctext.org/analects/xue-er/zh?en=on.

18 Ibid., https://ctext.org/analects/yang-huo/zh?en=on. 
and enlighten them, and encourage actions. "Knowing what will be in the future by understanding the past" suggests more explicitly that poetic language helps people learn by analogy, indicating the inspirational quality of poetic language. Poetic language conveys a more universal meaning than just naming of things. Such a quality is shown in the two paragraphs above.

In addition, the description of the status of poetry in the Mencius is also noticeable:

Mencius said, "The traces of sovereign rule were extinguished, and the royal odes ceased to be made. When those odes ceased to be made, then the Chun Qiu (Spring and Autumn/History) was produced". (Li Lou II, p. 21$)^{19}$

Originally, the poetry and history could be passed down because of the reign of sagely king of Zhou (周) and its influence. People either celebrated or criticized the kings' government in three kinds of literary forms, Feng (風), Ya (雅), and Song (頌). Later, when there was no more sagely king and the power of feudal princes was on the wane, Confucius started to edit Chun Qiu based on the documents from official historiographers, which troubled the treacherous ministers and traitors. Nevertheless, according to Qian $\mathrm{Mu}$, this process indicates that poetry and history have a common nature. Taking the Book of Poetry for example, this classic of Ancient China often depicts historic events and the number of such depictions even exceeds that in Shu Jing (書經, The Book of Documents) (Qian, 1073/1974). Qian Mu continues to point out that the literary works of Ancient China can be divided into three categories: history, argument, and poetry. However, the so-called “arguments” were usually written as poetic or historical works. He states that the story of peng (鵬) in Zhuangzi's "Xiao yao you" is an argument very much in the manner of poetry. As for the story of "Mencius meeting the King Hui of Liang", it is at the same time an argument and description of an event in history. Therefore, poetry and history are indeed the "pillars" of Chinese culture (Qian, 1968/1975, p. 12).

The Book of Poetry is full of historic events and the writing skills include " $F u$ " (賦, describing), "Bi" (比, comparing), and "Xin" (興, stimulating the mind). Whether a poet "plainly describes" something, "compares" one thing to another, or "stimulates the mind" with something, he or she is conveying a more universal meaning through the naming of things. As Qian Mu has compared poetry and history to the "pillars" of Chinese culture, the above mentioned exemplary languages, including history, argument, and poetry, are indeed unique features of Chinese culture. Moreover, we have demonstrated different subjectivity (such as "Mirror-reflection" and "Ren") with examples from Zhuangzi (Daoism), Confucius, and Mencius (Confucianism).

\section{Features of Exemplary Language and Characters}

This article focuses on the Western and Eastern exemplary languages and agrees that different types of exemplary language are "pillars" of Chinese culture. By contrast, exemplary language is not a mainstream way of expression in Western culture, which may stem from different types of character. Arendt has provided an example in The Life of the Mind. She states that the Chinese character “犬” (dog) is actually an image, but it can duplicate the concept of "dog" perfectly and turn the invisible idea into a vivid pictograph. She believes that this is different from Kant's statement in his schematism of the categories that "no image could ever be adequate to the concept (of dog in general)" (Arendt, 1976, p. 100). For Arendt, Kant is the representative figure of the Western viewpoint who maintains that an image can only represent a concept partially rather than completely. There were once pictographs in the Western culture, but they gradually disappeared and turned into words formed by letters (Arendt, 1976). Since Western languages often aim to justify a claim or sentence

19 Sturgeon (2011), https://ctext.org/mengzi/li-lou-ii/zh?en=on. 
(logon didonai), the logic operation of the justification proceeds in the linear time based of which the words are constructed. Thus, the mainstream of Western philosophy has developed based on this tradition. However, what are the differences of the Chinese and the Western cultural subjectivity suggested by the distinct ways of creating characters/words?

Both Qian Mu and Tang Jun-yi have pointed out that compared with Western words, Chinese characters can convey meanings more comprehensively. Qian Mu (1968/1975) believed that many meanings can be conveyed with the fewest Chinese characters. Tang Jun-yi comments on the "one-character-one-sound-one-meaning" quality of Chinese characters by quoting Zhang Tai-yan that "in the West, a word is with multiple sounds, so the people there form ideas slowly. A Chinese character has only one sound, so Chinese people form ideas fast". Tang is convinced that the Chinese are good at "forging" concepts, which is reflected by their literary construction of various conceptions and emotions as well as their philosophical thoughts (Tang, 1953/1974). The author believes that this ability of "cohesion" does not require the element of "time", by which the Western words are constructed. Instead, it combines the character with the concept directly through the referent. Kant once uses "Schemata" to connect sensation with understanding, elaborating on how a concept refers to the referent. In this process, "schemata" still contains abstract meanings and "time" plays an important role. However, Chinese characters are not schemata. Though they have to be recognized by sensation, the "cohesion" of meanings to make characters directly understood by intuition seems more crucial. It requires an ability just like the "intellectual intuition" (intellektuelle Anschauung) proposed by Kant.

Because "time" serves as a "connector" in constructing words and concepts, the mainstream tradition of Western philosophy is logon didonai. As what Qian Mu has said, this means replacing "arguments" with "poetry" and "history" is not commonly accepted. Nevertheless, Rhetoric and Poetics by Aristotle once led a non-mainstream trend. In addition, Augustine, Kierkegaard, Nietzsche, Arendt, Ricoeur, Kant (who emphasizes the effects of an example and analogy), and Heidegger all continue this trend in different ways, focusing on different issues. Interestingly, "linear time" is still a significant element in this non-mainstream way of expressing. For example, Augustine explored his relation with God in Confessions by reflecting on the issue of time. Nietzsche proposed "die ewige Wiederkunft" (the eternal return), indicating that there was a kind of eternity in the moment when the past and the future intersected; the moment transcended but was never detached from the time in which humans lived. As for the narrative of humans who act, Arendt believes that it constructs a tangible public space and time and enables the immortality of humans. This kind of time is different from the time of labor, which is physical and forever-cycling, and the continuous time that cannot be guaranteed in which humans construct the world by working. It is clear that Arendt also considers this non-mainstream way of expressing in the framework of time. Ricoeur puts even more attention on the time of narrative. Just as what has been discussed earlier, a narrative is composed of time and meaning. The "time" here is a combination of subjective time and objective time, and objective time is linear time. Linear time is a key element in the forming of words. Therefore, narrative is still within the framework of linear time.

Chinese characters, on the contrary, demonstrate a mental ability of gathering and forging meanings. Can it thus break away from the limit of linear time? Are the allegories and poetic histories told in Daoist and Confucian classics without "time" and "meaning" as the main elements constructing the stories? Chinese culture values history. Isn't the element of "time", in which everything in the history happens, seen in the description of history? The subjective time in the narrative analyzed by Ricoeur is about the relation between a 
human and his/her surroundings, as well as the consequential consciousness of time. Philosophers in the West, such as Augustine, Husserl, and Heidegger, have varied opinions on this issue. The author of this article believes that Chinese culture adopts the subjective type of time just like what Ricoeur proposed. The "no time and space is with nothing" in Chinese cosmology pointed out by Tan Jun-yi several decades ago is an excellent example. He started from the standpoint that humans can sense all things. By such sensing, humans can know the correlation among and process of the transformation of all things. In this case, space is like the relative "location" of one thing to the others, without an absolute definition of "here" or "there". Time, rather than a definite moment, serves as a "consequence" in which one thing raises or succeeds the others. Without sensing of humans, there are just "pure locations" and "coordinates" indicating the space-time from the one dimension to the three dimensions (Tang, 1953/1974). The latter is the so-called "objective time", which is opposite to "subjective time".

Chinese characters are not with multiple syllables, so the creation of them does not rely on linear time; instead, Chinese characters gather and forge meanings with an intellectual intuition. Such ability is made possible by the subjective time mentioned above (sensing things around) and will surely be demonstrated in the descriptions of history. Therefore, if we are going to talk about the "narrative" in the context of Chinese culture, the "time" is definitely the feature of it because of the unique subjectivity of the culture. Ricoeur maintains that a narrative consists of time and meaning. The "time" here should be discussed individually.

In this article, we explore the distinction between the Chinese and the Western exemplary languages. "Time" is one of the elements that cause the difference. As for the other element, meaning, we have discussed the subjectivity of Daoism ("Mirror-reflection") and Confucianism ("Ren"), and the meanings they represent through different types of allegories. The Western people still tend to focus on personal guilt and tragedies of roles, relying on narrative to challenge the grief, chaos, and confusion. By contrast, in Chinese culture, the functions of narrative include to stimulate the mind, to do self-contemplation, to teach the art of sociability, to show how to regulate feelings of resentment, to learn how to serve one's father and prince, and to praise or criticize the king's government. If we follow Aristotle's Poetics to focus our discussion on drama, which is considered by Ricoeur to be a type of narrative in a broad sense, then the differences between the Chinese and the Western novels/dramas are just as what have been pointed out by Tang Jun-yi. That is, a Western drama normally develops its plot by shaping a hero's personality and ideal or concerning certain social problems. As for the dramas in the history of China, an individual or a single purpose is typically not the primary focus. Instead, a Chinese drama usually puts attention to depicting a big picture of human society, indirectly shaping each role's personality and manner (Tang, 1953/1974). A Western drama often presents a tragedy in which an individual finally meets his or her end, while it has a cathartic effect on the audience's minds. A Chinese drama, though, tends to depict a whole human society where tragedies strike, the story usually ends with a realistic world where the pain has been transcended. This is because the Chinese cannot bear to see a "pure spiritual world that is not supported by the realistic one" (Tang, 1953/1974, pp. 258-260). The subjectivity of Daoism and Confucianism will be great examples, which have carried out this common "meaning" respectively through different life philosophies they have developed.

\section{Conclusion}

This article explores the recently popular topic, narrative, from the perspective of exemplary language in a broad sense. The concept of narrative has become more and more significant in philosophy, psychology, 
nursing, communication studies, and so on. However, when using the concept of narrative, one should understand first the theoretical background, keep the differences between cultures in mind, and reflect on the issue of applicability when adopting the narrative theories from the West.

This article has pointed out some Western philosophers who emphasize the importance of exemplary language and narrative, and elaborated on the theory of Ricoeur, who has inherited Arendt's narrative discourse. This article has also listed many examples of metaphorical language, words from valued writers/figures, words like the water in the cup, and histories in poetic form from the Zhuangzi (Daoism) and the Four Books (Confucianism). The meanings of these examples have also been elaborated on. Then, we compare the distinct ways of constructing characters/words in Chinese culture and the Western culture, tracing the origins their different subjectivity. We also analyze the elements of a narrative: time and meaning, and find that "linear time" (or objective time) still plays a significant role in the Western culture. By contrast, subjective time seems more dominant in Chinese culture. As for the meaning, there are different purposes and ways of using narrative in Chinese culture and the Western culture. Such differences also exist between Daoism and Confucianism due to distinct subjectivity.

\section{References}

Arendt, H. (1958). The human condition. Chicago: the University of Chicago Press.

Arendt, H. (1976). The life of the mind-The groundbreaking investigation of how we think. San Diego, New York. London: Harcourt Inc.

Arendt, H. (2003). Responsibility and judgment (with an Introduction by Jerome Kohn). New York: Schocken.

Arendt, H. (2012). Das Urteil. Texte zu Kants politischer philopsphie. Dritter Teil zu "Vom Leben des Geistes". München/Zürich: Piper.

Gadamer, H. G. (1990). Wahrheit und Methode, Grundzüge einer philosophischen Hermeneutik. Tübingen: Mohr.

Heidegger, M. (1982). Identität und differenz. Pfullingen: Neske.

Huang, J. H. (1974/2011). Xin yi Zhuangzi du ben (新譯莊子讀本). Taipei: San Min Book.

Kant, I. (1974). Kritik der urteilskraft. Hamburg: Meiner.

Kant, I. (1976). Kritik der reinen Vernunft. Hamburg: Meiner.

Kearney, R. (2004). On Paul Ricoeur: The owl of Minerva. London: Ashgate.

Kristeva, J. (2001). Hannah Arendt: Life is a narrative. Toronto/Buffalo/London: University of Toronto Press.

Qian, M. (1073/1794). Zhong guo shi xue ming zhu (I) (中國史學名著 (一)). Taipei: San Min Book.

Qian, M. (1968/1975). Zhong guo wen xue jiang yan ji (中國文學講演集). Taipei: San Min Book.

Ricoeur, P. (1984). Time and narrative, Vol I. (K. McLaughlin and D. Pellauer, Trans.). Chicago/London: The University of Chicago Press.

Ricoeur, P. (1988). Time and narrative, Vol. III, Section I-The Aporetics of Temporality. (K. McLaughlin and D. Pellauer, Trans.). Chicago/London: The University of Chicago Press.

Tang, J. Y. (1953/1974). Zhong guo wen hua zhi jing shen jia zhi (中國文化之精神價值). Taipei: Chen Chung Book.

Tzu, C., \& Tzu, L. (1962). The sacred books of China: The texts of Taoism. (J. Legge, Trans., F. M. Müller, Ed.). Mineola, New York: Dover Publications.

Xie, B. Y. (Ed. and Trans.). (1987/2006). Xin yi si shu du ben (新譯四書讀本). Taipei: San Min Book.

Zahavi, D. (2016). Self \& other: Exploring subjectivity, empathy, and shame. Oxford: Oxford University Press.

Zhan, K. (2014). Zheng lun zhong de Zhuangzi zhu ti lun (爭論中的莊子主體論). Taipei: Student Book. 